\title{
The mammalian fetal membranes*
}

\author{
J. S. Perry \\ A.R.C. Institute of Animal Physiology, Babraham, Cambridge CB2 4AT, U.K.
}

\section{Introduction}

Some of my colleagues entering the field of reproductive physiology have expressed dismay at the bewildering variety of structures involved in the maintenance of pregnancy in different species. They have also expressed a certain exasperation with the terminology used in describing it. This essay was written to provide them with a very broad picture and to facilitate their accumulation of detail in selected areas. It has proved useful to beginners, to some who are not primarily biologists and to some biologists who have found this part of the subject indigestible because its literature is scattered and difficult of access. The latter complaint has meanwhile been alleviated by the publication of Comparative Placentology (Steven, 1975) which offers a guide to further reading. References have been confined to a few of the classic texts, with some more recent publications that will provide access to the bulk of the relevant literature. For those entering on serious study of mammalian embryology or comparative placentology, this essay can only serve as an introductory survey, a preface to the literature. It deals only with structure and will not (in the words of the Editor of the book just referred to) "encourage that most dangerous of anatomical pursuits, the prediction of function from structure". The study of function depends on experiment, but knowledge of the structures involved is a prerequisite of planned experiment, and in no other area of mammalian physiology is there such variety as is to be found in the means by which animals of different species contrive to retain, nurture and finally expel their young.

\section{General}

\section{The blastocyst, implantation and the fetal membranes}

The fertilized egg, the zygote (the ovum is the unfertilized gamete), of all mammals is surrounded by a mucopolysaccharide coat - the zona pellucida - which is transparent, tough and elastic. Inside this the zygote divides as it passes through the oviduct (Fallopian tube in man), so forming a solid clump of cells, the morula. This is soon transformed into a hollow ball of cells, the blastocyst, and its wall becomes two-layered; the cavity is known as the blastocoele (Text-fig. 1).

In laboratory parlance, and even in print, the oocyte (the gamete up to the time of mitotic division to produce the first polar body), ovum, zygote, morula and blastocyst are frequently referred to indiscriminately as the 'egg'. The term 'blastocyst', apparently invented to circumvent the difficulty of relating this stage in mammalian development to the blastula and gastrula of other vertebrates, is applicable to this hollow ball of cells both before and after the development of the inner layer (endoderm). The embryo will form from a thicker portion of the ectoderm, known as the embryonic knot or disc. The orientation of the embryonic disc in relation to the symmetry of the uterus is a species characteristic. The remaining part of the ectoderm is the

* Requests for reprints should be sent, with a per copy remittance of $£ 1.00$ (US $\$ 2.50$ ) for <10 copies, $£ 0.75$ (US $\$ 1.90$ ) for $10-50$ copies and $£ 0.50$ (US $\$ 1.25$ ) for $>50$ copies, to Journal of Reproduction \& Fertility, P.O. Box 32, Whitehall Industrial Estate, Colchester, Essex CO2 8HP, U.K. 
(a)

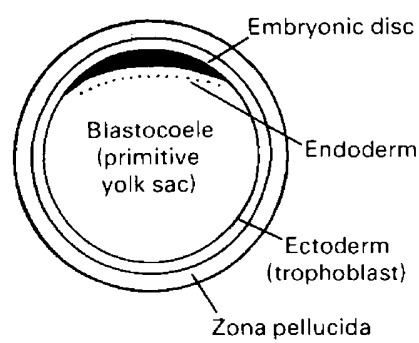

(b)

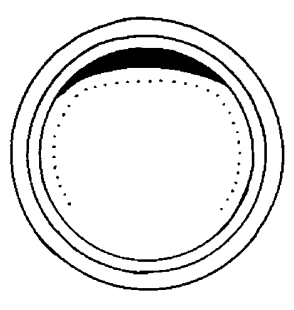

(c)

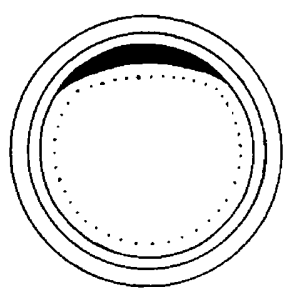

Text-fig. 1. The endoderm is first differentiated from the ectoderm beneath the embryonic disc (a) and later extends over the inner surface (b) to enclose the blastocoele (c) as the primitive yolk sac.

trophoblast (from a Greek root meaning feeding or nourishing layer) which plays an important, indeed the leading, part in the formation and structure of the placenta.

The transformation from morula to blastocyst usually occurs soon after the 'egg' has reached the uterine lumen. The inner (endodermal) layer of cells in the bilaminar blastocyst usually forms by tangential division of a few cells of the embryonic disc; these first endodermal cells then 'spread' around the inner face of the ectoderm and the blastocoele thus becomes the yolk sac. After this the zona pellucida (often referred to simply as 'the zona') is lost. Even the way in which this is accomplished differs in different species. In some (e.g. cow) the zona splits and the contents are extruded ('hatched'); in others the zona appears to be dissolved in situ, by a process that seems to involve lytic enzyme action and may require the participation of both uterine and embryonic tissues.

With the loss of the zona pellucida development enters on a new phase, and from this point the mammals of the different orders (Rodentia, Carnivora, Artiodactyla, etc.) exhibit great diversity both in the mode of development and in the final form of the fetal membranes and the placenta. The fetal membranes comprise the amnion, yolk sac, chorion and allantois-structures of fetal (embryonic) origin interposed between embryo (or fetus) and mother. These structures, together with the fetus itself, i.e. the whole of the products of conception, are sometimes referred to collectively as the conceptus. A placenta is formed when fetal tissues acquire contact or fusion with maternal tissue for physiological exchange. In mammals this always involves the chorion and either the yolk sac or the allantois. The amnion remains avascular, and its function is chiefly mechanical. In the early stages it is turgid under the hydrostatic pressure of its contained fluid, and so provides the 'private pond' within which the embryo develops, free from any local pressure on its surface.

The development of the fetal membranes is to some extent governed by the mode of implantation (sometimes called nidation) and this itself varies widely between species. The terms 'superficial' and 'interstitial' distinguish between those in which the blastocyst remains in the uterine lumen and those in which it penetrates the luminal epithelium and embeds itself in the uterine wall. In 'superficial' implantation the blastocyst usually becomes distended, more or less filling and often swelling the uterine lumen before the trophoblast attaches to or attacks the luminal epithelium. In 'interstitial' implantation the blastocyst remains small, usually lodges in a groove or fold of the uterine mucosa and (by means not yet clear) passes through the luminal epithelium and develops in the endometrial stroma. The cells in the vicinity of the blastocyst, in this type of implantation, react to the presence of the embryonic tissue in a characteristic manner. This 'decidual reaction' is so called because the cells involved are among the maternal tissue (decidua) that is shed or lost during gestation or at parturition.

Superficial implantation is usually associated with an amnion formed by folding, as in the rabbit, the dog and cat (Pl. 1, Figs la and $1 \mathrm{~b}$; Pl. 7, Figs 15 and 16) and the pig. Interstitial 
implantation is associated with amniogenesis by cavitation, i.e. by a slit appearing within the ectoderm, as in the mouse and the guinea-pig (Pl. 1, Figs 1c and 1d; see also Plates 5 and 6). Various attempts have been made to identify an evolutionary trend between and within these broad categories (see Mossman, 1937), but contemporary interest centres principally on the immunological and endocrinological properties of the chorion and its derivatives. There are also intermediate types of amniogenesis, but by whatever means it is formed the amnion always constitutes a close-fitting, thin, tough membrane, at first filled with fluid under slight pressure, in which the fetus 'floats'. The amnion later becomes less turgid but it is always retained until term. Both ends of the fetal alimentary canal open into the amniotic cavity and are thus isolated from communication with any other cavity or fluid. In contrast to the amnion, the yolk sac, chorion and allantois vary greatly in their final condition as well as in their formation.

A placenta formed by the chorion and vascularized by the allantois (an allanto-chorionic placenta) is the definitive organ of attachment and fetal nourishment in all eutherian mammals, but its development is often preceded by that of a 'choriovitelline' placenta, formed where the (vascular) yolk sac combines with the chorion. These generalizations are best explained through particular examples, a number of which are described in the following sections.

\section{The fetal membranes of the pig}

As the pig has the simplest of the known eutherian placental types, its development and structure provide a useful basis from which to derive the sequence of events in other species. Placental development, however, cannot be considered in isolation from that of the embryo itself, and in the pig much has to happen before an intimate connection between chorion and uterine lining is achieved. First, as the blastocyst enlarges, it loses its zona pellucida and by about 10 days post coitum (p.c.) it has the form of a flaccid sphere $8-10 \mathrm{~mm}$ in diameter. At this stage the trophoblast cells, as seen in sections of fixed material, are roughly brick-shaped but the endoderm cells that form the lining layer are far fewer in number and are spread to form a very thin sheet; the endodermal lining of the blastocyst at this stage, and for several days beyond, is interrupted in places (Pl. 8, Fig. 19). As the electron micrograph shows, the outer surface of the blastocyst bears many long slender microvilli. The blastocysts are distributed along the uterine horns (Text-fig. 2), having apparently been dispersed by peristaltic movements of the uterine wall. This muscular activity appears to continue, but the blastocysts come to rest and seem to adhere to the uterine wall near the attachment of the mesometrium. They are extremely 'tacky' but there is as yet no cell-to-cell connection between the trophoblast and the uterine lining. Next, in the pig, the spherical blastocyst is transformed, over a period of 1 or 2 days, into a long tube of minute diameter, first passing rapidly through a period when it is seen as an ovoid and then a sausage-shaped object, elongating in much the same way as does a ball of plasticene rolled under the hand (see Heuser \& Streeter, 1929; Patten, 1948, for photographs). It is difficult to envisage the manner in which this may be achieved, but the rapidity of the elongation and the reduction in diameter that accompanies it suggest that it is by deformation rather than by cell division, although it has often been referred to as the 'rapid growth' of the blastocyst. The elongated blastocyst is always found aligned with the insertion of the mesometrium (the suspensory ligament of the uterine horn, the 'broad ligament' of medical parlance) and within a few days a hyperaemic tract is clearly seen on the surface of the uterine lumen where the blastocyst is lodged (see Perry \& Rowlands, 1962). As the mucosal surface is greatly folded the blastocyst may attain a length of a metre or more while occupying only $20-30 \mathrm{~cm}$ of uterine horn.

Text-figure 2 is, of course, very diagrammatic. The uterine horns of the pig do not extend in a ' $V$ ' unless they are so arranged after being dissected free of the mesometrium, and although the blastocysts occupy almost the whole length of the uterine horns, they do not fill the uterine lumen at this stage, and are actually in contact with only a small fraction of the mucosal surface area (Pl. 8, Fig. 20). They rarely overlap to any great extent, but appear to elongate until they 


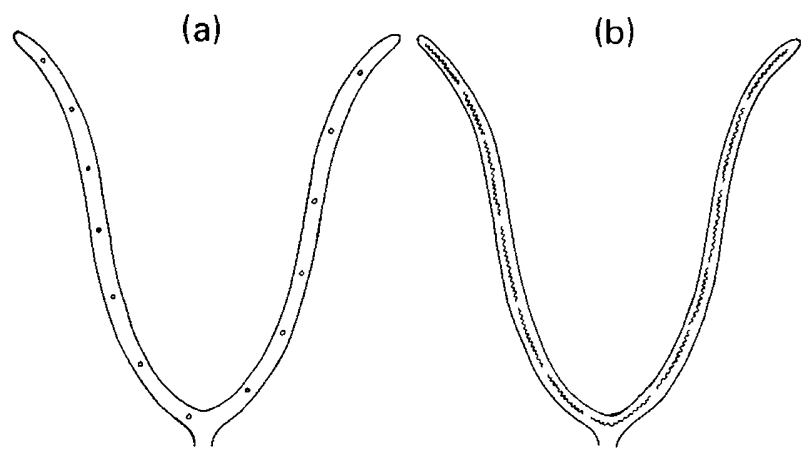

Text-fig. 2. Distribution and 'growth' of blastocysts in the pig. The spherical blastocysts become fairly evenly distributed along the uterine horns by the 10th day p.c. (a). Soon afterwards they elongate to occupy the whole length of the uterine horns (b).

are in contact with their neighbours or nearly so (Text-fig. 2b). Pig blastocysts tend, therefore, to be longer when they are fewer. They are distributed along the whole uterine length from ovary to ovary, and the one nearest the body of the uterus usually extends into the opposite horn. In this respect, therefore, the right and left horns do not operate independently and the uterus of the pig behaves as a single unit. By the 18th day of pregnancy the surface microvilli have disappeared and the first adherence of trophoblast to uterine epithelium occurs at isolated points on the surface (Pl. 8, Fig. 21). The definitive attachment by closely interlocked maternal and fetal microvilli over the whole interareolar surface develops within a day.

Experiments involving partial hysterectomy in the pig (du Mesnil du Buisson, 1961; and see Perry, 1971) showed that the continuance of pregnancy beyond the duration of the oestrous cycle depended on this fetal occupancy of the whole length of the uterine horns. It apparently prevents the production of a uterine factor, probably a prostaglandin, which in the non-pregnant animal causes the corpora lutea to regress and cease to produce progesterone. A similar condition holds true in the ruminants and Fig. 17 (Pl. 7) shows the conceptus of a cow 42 days after mating. The embryo in its amnion is only about $25 \mathrm{~mm}$ long, but the allantochorionic sac extends to the tip of the 'pregnant' horn and a long way into the other horn. Beyond this can be seen the degenerating tip of the elongated blastocyst which reached the ovarian extremity of this 'empty' horn.

Cell division continues in the embryonic tissues and after their sudden elongation the blastocysts of the pig steadily increase in circumference. At the stage of development represented in Text-fig. 1 the embryonic area is simply a slightly thicker part of the ectodermal layer, and it is still in much the same condition immediately after elongation of the blastocyst. Soon after elongation, however, the first mesodermal cells appear-'budded' from the ectoderm of the embryonic disc to form a thin sheet of tissue between it and the underlying endoderm, as shown in transverse section in Pl. 1, Fig. 2(a). This sheet of tissue increases in area and soon extends beyond the margins of the embryonic disc. Its central portion, within the embryonic area, will be incorporated into the structure of the developing embryo; the 'extra-embryonic' portion plays an important part in the formation of the fetal membranes.

Soon after the outgrowth of the extra-embryonic mesoderm, a split appears in it so that it becomes two layered, one layer closely overlying the endoderm, the other underlying the ectoderm near the developing embryo (Pl. 1, Fig. 2b). The cavity so formed is the extra-embryonic coelom, or exocoele. The outer layer of mesoderm is raised, together with the covering ectoderm, in a ridge, the amniotic fold, around the embryonic disc as shown in Pl. 1, Fig. 2(c) (c.f. Pl. 1, Fig. 1b). As the amniotic folds to the left and right of the embryonic disc grow and fuse above it (Pl. 1, Figs $2 \mathrm{~d}$ and 2e) the amnion is formed and is separated from the chorion. At the same time this disc, or plate, is transformed into a tube, open along its base. 
Where the mesoderm covers yolk-sac endoderm it constitutes a splanchnopleure; where it lines the ectoderm (trophoblast) it is a somatopleure. This outer layer of mesoderm and the overlying trophoblast together constitute the chorion (Pl. 1, Fig. 2d), which has a key role in the placenta of all mammalian species although its further development takes widely diverse forms. The inner mesodermal lining of the exocoele, closely applied to the yolk sac (the yolk-sac splanchnopleure), also has an important function for it is in this layer that blood islands, and soon afterwards blood vessels, are first formed. Such blood islands are seen in the yolk-sac splanchnopleure of the cat shown in Pl. 7, Fig. 15. In many species the limit of the mesodermal penetration between the yolk-sac endoderm and the trophoblast is marked by a prominent annular blood vessel, the sinus terminalis. There is no particularly conspicuous blood vessel in this position in the pig, however, and in this species the exocoele expands almost as the mesoderm advances (Pl. 1, Fig. 2), so that there is a very limited area which is trilaminar, and therefore most of the yolk-sac wall remaining in contact with the trophoblast is not vascular.

The developments indicated in Pl. 1, Fig. 2 (b to e) extend from about the 13th to the 17th day post coitum in the pig. The diagrams ignore the differentiation that proceeds within the embryo itself during this period (for this, refer to Patten, 1948). In these few days the ectoderm of the embryonic disc has formed the neural tube and the beginnings of a nervous system, the mesoderm has formed somites (the beginnings of the vertebrae and the muscle system) and the rudimentary heart and blood vessels. The yolk sac reaches its maximum development about Day 18 (Pl. 2, Fig. 3) and after its isolation from the trophoblast by the expansion of the exocoele the yolk sac rapidly shrinks, becoming relatively inconspicuous by Day 20 . The diagrams in Pl. 1, Fig. 2 are of transverse sections, illustrating how the amnion is formed and how it, and the embryo, are progressively 'pinched off' from the yolk sac. Plate 2, Figs 3 and 4 are from longitudinal sections, representing gestational ages of about 18 and 21 days respectively. Near the posterior end of the embryo, behind the opening that still connects the gut with the yolk sac, an outgrowth of the gut protrudes into the exocoele, pushing the mesoderm in front of it (Pl. 2, Fig. 3). This extension of the gut is the allantois. In the very early stages of its development in the pig it has a characteristic 'Napoleon's hat' shape, hinted at in the diagram, with upturned ends less distended than the more central part. Like the yolk sac, it is a thin-walled sac lined by endoderm and covered by mesoderm. It will receive fetal urine and its stalk will eventually form part of the urinary bladder.

The pig conceptus, 18 days after mating, is a tubular structure from $\frac{1}{2}$ to $2 \mathrm{~m}$ in length and about $2 \mathrm{~mm}$ in diameter. The embryo has about 32 somites, the heart has begun to beat and blood circulates to and from the annular chorio-vitelline placenta. As the exocoele extends beneath the yolk sac the latter loses its contact with the trophoblast and is separated from the chorion (Pl. 1, Fig. 2; Pl. 2, Fig. 3); the allantois swells and the long cylindrical form is changed to that of a shorter and very much more distended fusiform sac, which can now be drawn at approximately its natural size (Pl. 2, Fig. 4). The expanding allantois soon fills the exocoele except along one side of the embryo, where the amnion remains in contact with chorion. The mesoderm covering the allantois fuses with that which lines the chorion, so the resulting allanto-chorion has an outer layer of ectoderm, an inner layer of endoderm, and mesodermal tissue between them. The ectoderm is the trophoblast which, in the pig, remains only one cell deep. It takes the form of an epithelium standing on a basal lamina, and 'tight junctions' eventually bridge the intercellular channels; in the earlier stages of development the trophoblast cells are connected only by desmosomes (Pl. 8, Fig. 19). The endoderm also remains single-layered and forms an epithelial lining to the allantois. The intervening mesoderm carries the extra-embryonic blood vessels which ramify over the whole allanto-chorionic sac except at its extremities. From about Day 18 of pregnancy until term, the allanto-chorionic sac is firmly adherent to the uterine wall, but the uterine luminal epithelium remains intact in the pig. The attachment is effected by interlocking microvilli of the trophoblast cells and the luminal epithelial cells. It is interrupted only in specialized areas, the 'regular' and 'irregular' areolae. 
Plate 7, Figs 15 and 16 show some similarities and many differences in early development between pig and cat. In the cat implantation is 'central', the blastocyst remains spherical as it expands and the uterine glands hypertrophy over the whole area of contact. Plate 7, Fig. 15 shows a transverse section passing through the posterior part of an embryo near mid-pregnancy. At this point the amniotic folds have closed and the sero-amniotic connection has been lost (Pl. 1, Fig. 2). The gut has been closed off from the yolk sac, the yolk-sac stalk being anterior to this section, but the body wall has not yet closed beneath the embryo in this region, so the embryonic coelom is still continuous with the exocoele. Above the embryo the chorion is closely applied to the hypertrophied glandular uterine lining, while below it lies the yolk sac which is occupying most of the uterine lumen. A fold in its wall results in the yolk sac appearing twice in this section. Blood islands are prominent in the mesoderm covering the yolk sac in the vicinity of the embryo. Plate 7, Fig. 16 represents a later stage in the cat's development and the section passes through the embryo at two levels because of the torsion normal to this stage in mammals. By this time the exocoele has expanded at the expense of the yolk sac, and the blood islands have developed to form vitelline blood vessels. The amnion encloses the embryo; the yolk-sac endoderm passes 'beneath' the amnion in the posterior region where the exocoele has not yet penetrated between yolk sac and amnion. Thus the bilaminar sheath which encloses the embryo is composed of endoderm over ectoderm in the posterior region and mesoderm over ectoderm in the major part.

\section{The fetal membranes of the guinea-pig}

The guinea-pig affords a good example to contrast with the pig both in the mode of implantation and in the form of the definitive placenta. In the guinea-pig, and in the murine rodents, implantation is interstitial (Pl. 1, Figs $1 \mathrm{c}$ and $1 \mathrm{~d}$ ) and the yolk sac is said to be 'inverted'. This term refers to the fact that the endoderm is outside the mesoderm. This comes about by a process which may be imagined as the invagination of a hollow ball to form a double-walled cup, followed by dissolution of the outer wall of the cup, thus exposing the surface which was originally the inside surface of the ball. This is shown in section in Text-fig. 3.

(a)

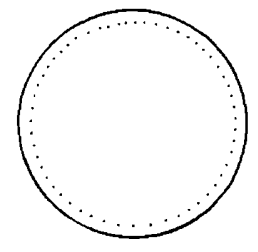

- Ectoderm (b)

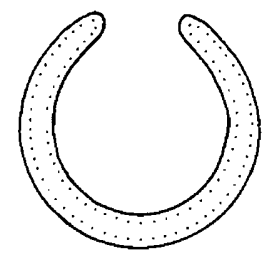

......... Endoderm (c)

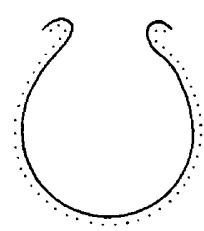

Text-fig. 3. Diagrammatic representation of the 'inversion of the germ-layers'.

The tiny blastocyst (less than $200 \mu \mathrm{m}$ diameter) lodges in a groove in the uterine lumen (anti-mesometrially, see Pl. 1, Fig. 1c; Text-fig. 4). It penetrates the uterine epithelium and finds itself in the 'decidua', a thick cushion formed by hypertrophy of the uterine wall at the point of implantation (Text-fig. 4; Pl. 6, Fig. 13). A substantial part of this cushion consists of characteristic polyploid cells. These are specifically referred to as 'decidual cells' and their formation in response to the presence of blastocyst (or other 'foreign body' which induces a deciduoma rather than a decidua) is what the term 'decidual cell reaction', or DCR, refers to. Text-figure 4 represents a longitudinal section through the guinea-pig uterus at an implantation site. No attempt is made in this diagram to distinguish the 'primordial germ layers', i.e. ectoderm, mesoderm and endoderm, because of the minute size of the embryo. Their development is traced in more detail below. 

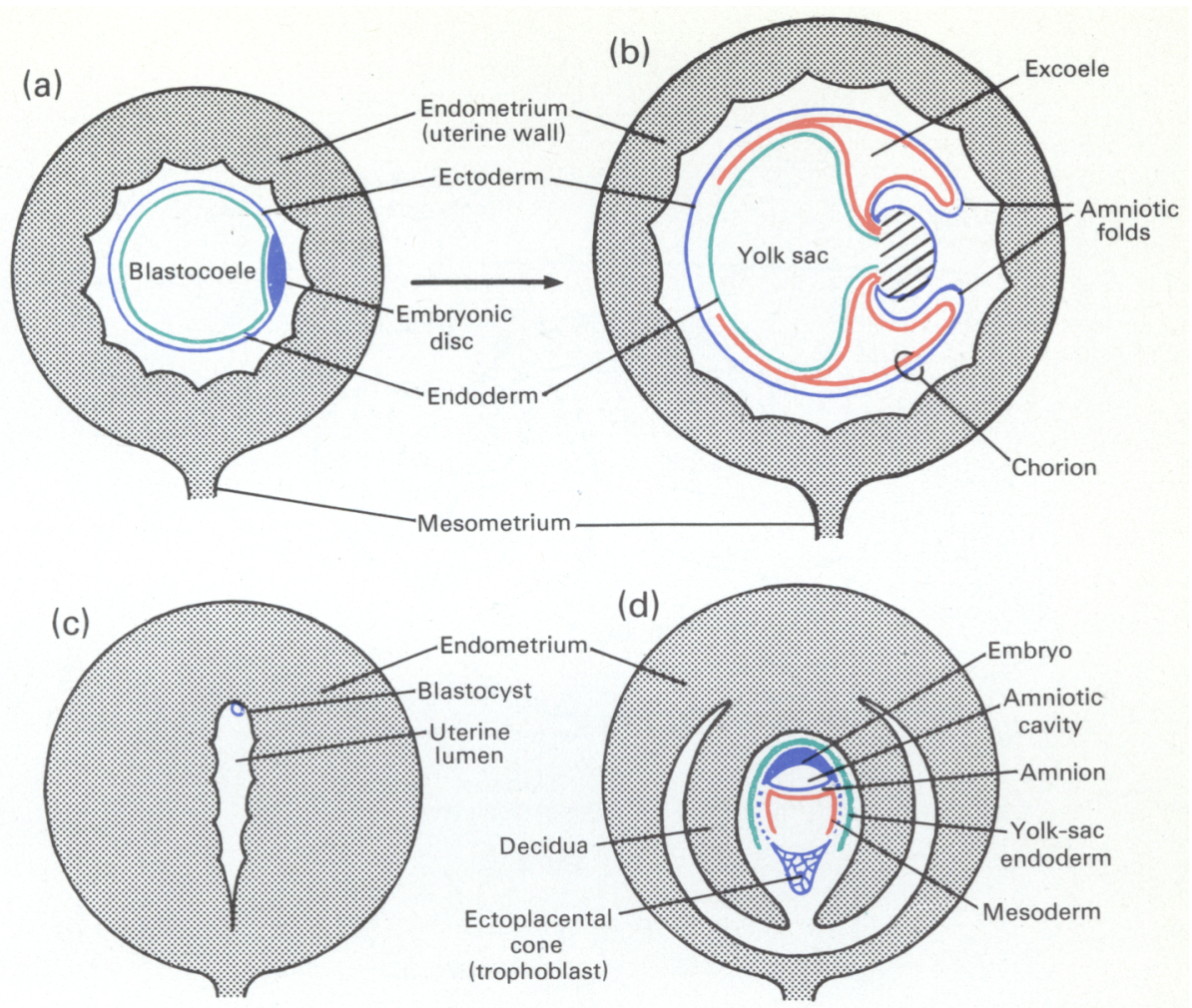

Fig. 1.

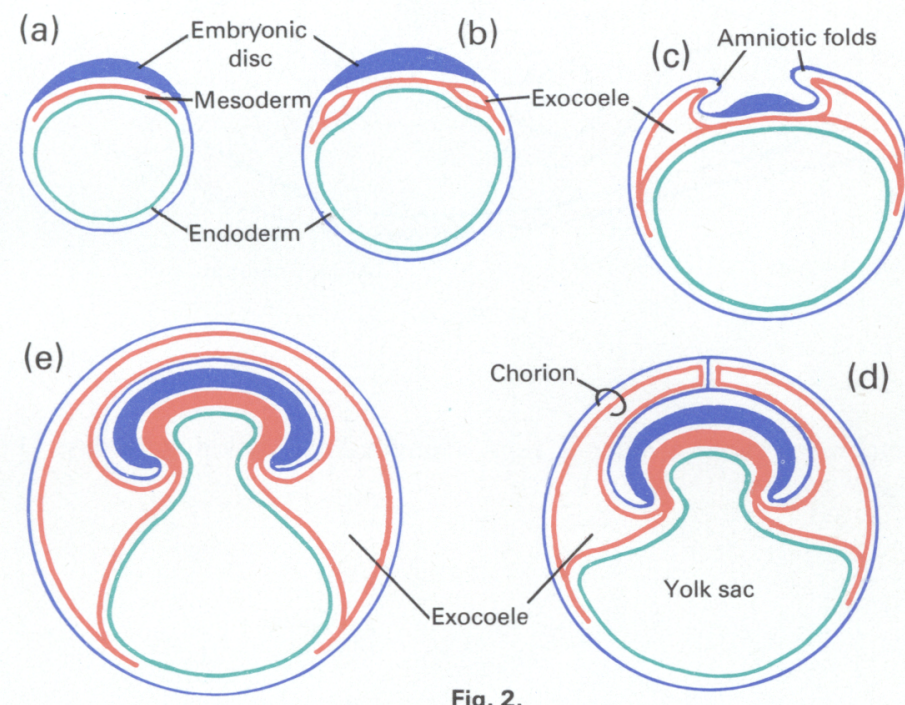

Fig. 2.

Fig. 1. (a, b) Central implantation and the formation of amniotic folds; orientation of the embryo as in the dog. (c, d) Interstitial implantation and the formation of the amnion by cavitation as in the guinea-pig.

Fig. 2. Further development of the amnion and chorion, and the extension of the exocoele around the yolk sac, as in the pig (transverse section). In (d) the amniotic folds have met but not

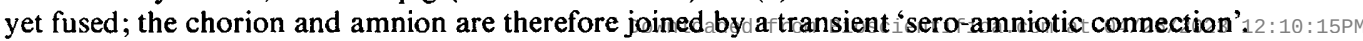




\section{PLATE 2}

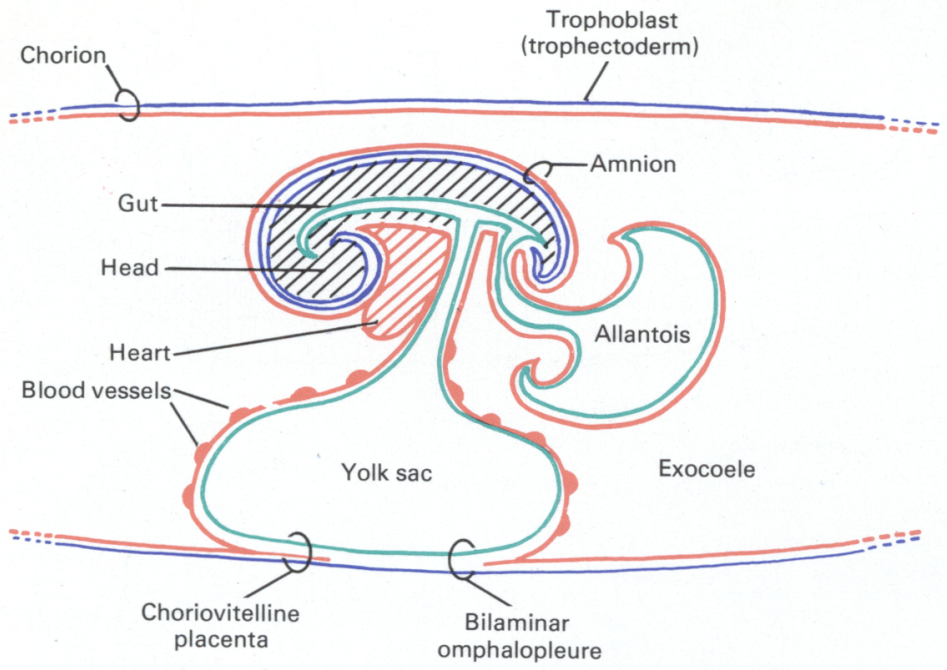

Fig. 3.

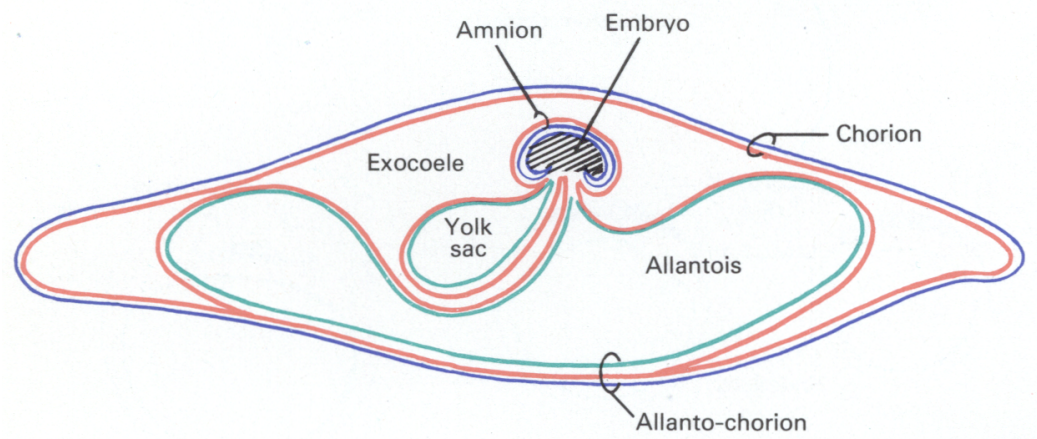

Fig. 4.

Figs 3 and 4. Fetal membranes of the pig, as in a longitudinal section at 18 days (Fig. 3) and at 21 days (Fig. 4) post coitum. 


\section{PLATE 3}

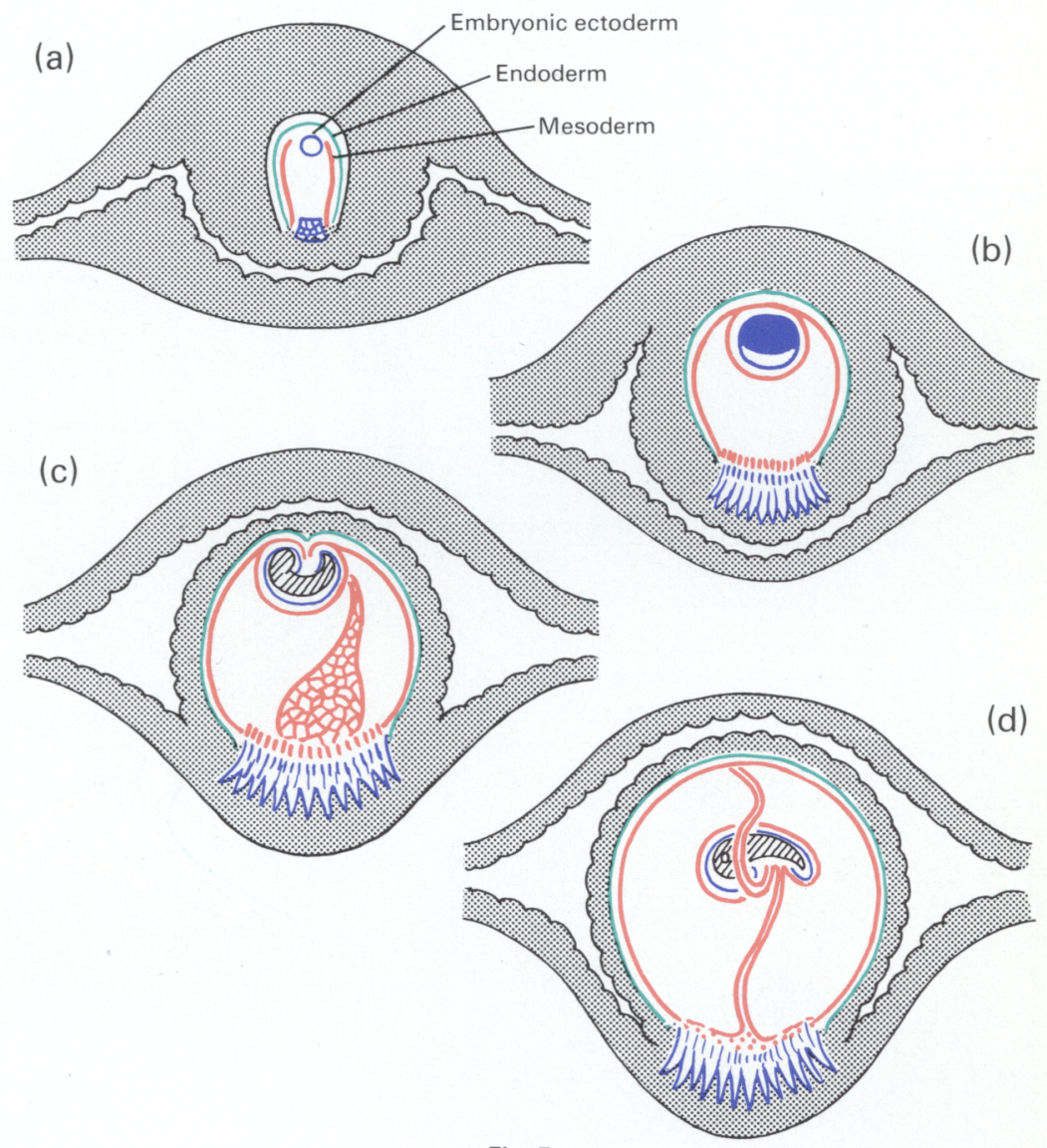

Fig. 5.

Fig. 5. Development of the fetal membranes, and changes in relationship to the decidua, in the guinea-pig. 


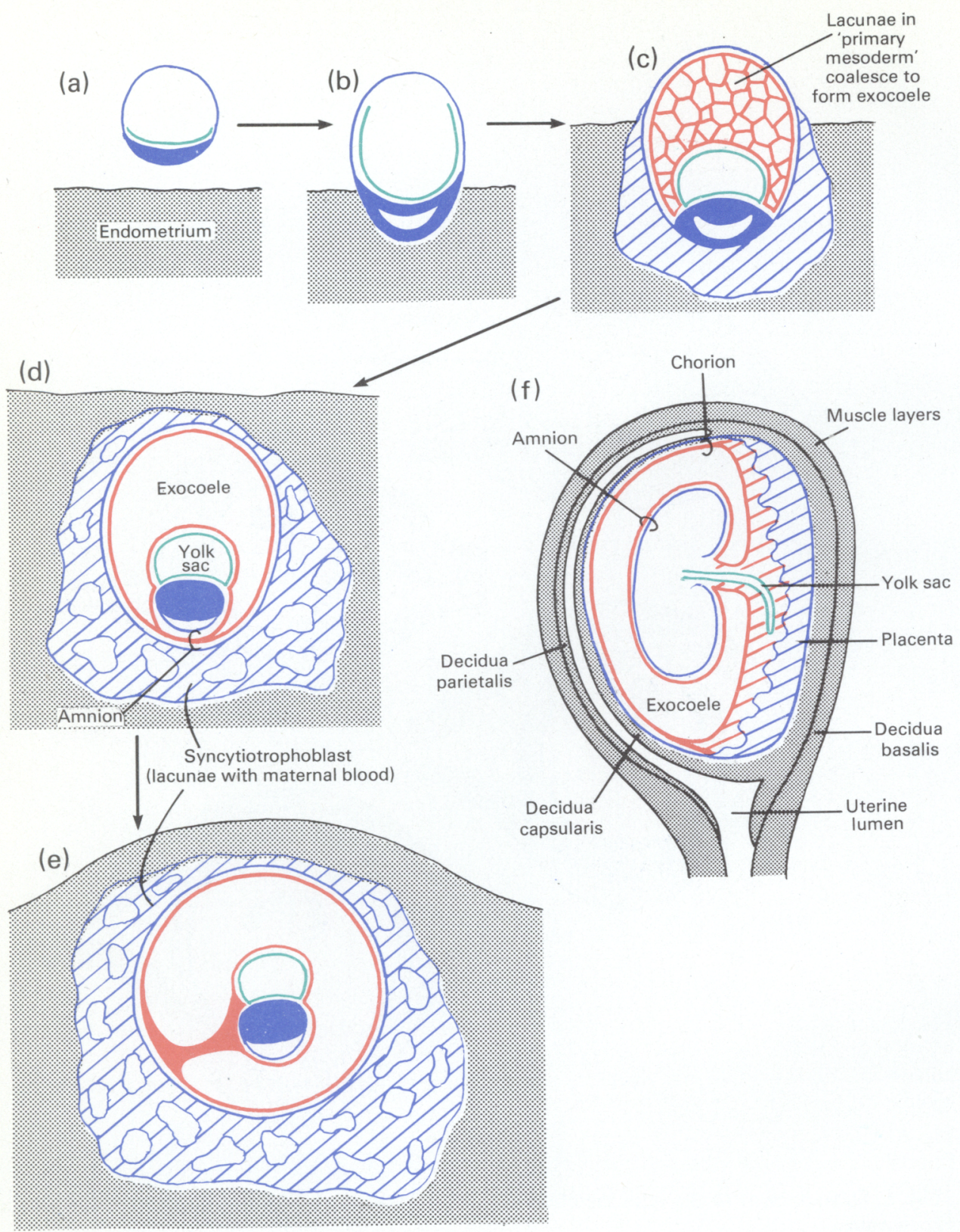

Fig. 6.

Fig. 6. Implantation and the precocious development of the amnion and chorion in man. The yolk sac is reduced to about $3 \mathrm{~mm}$ diameter by the 12 th week of pregnancy. 
PLATE 5
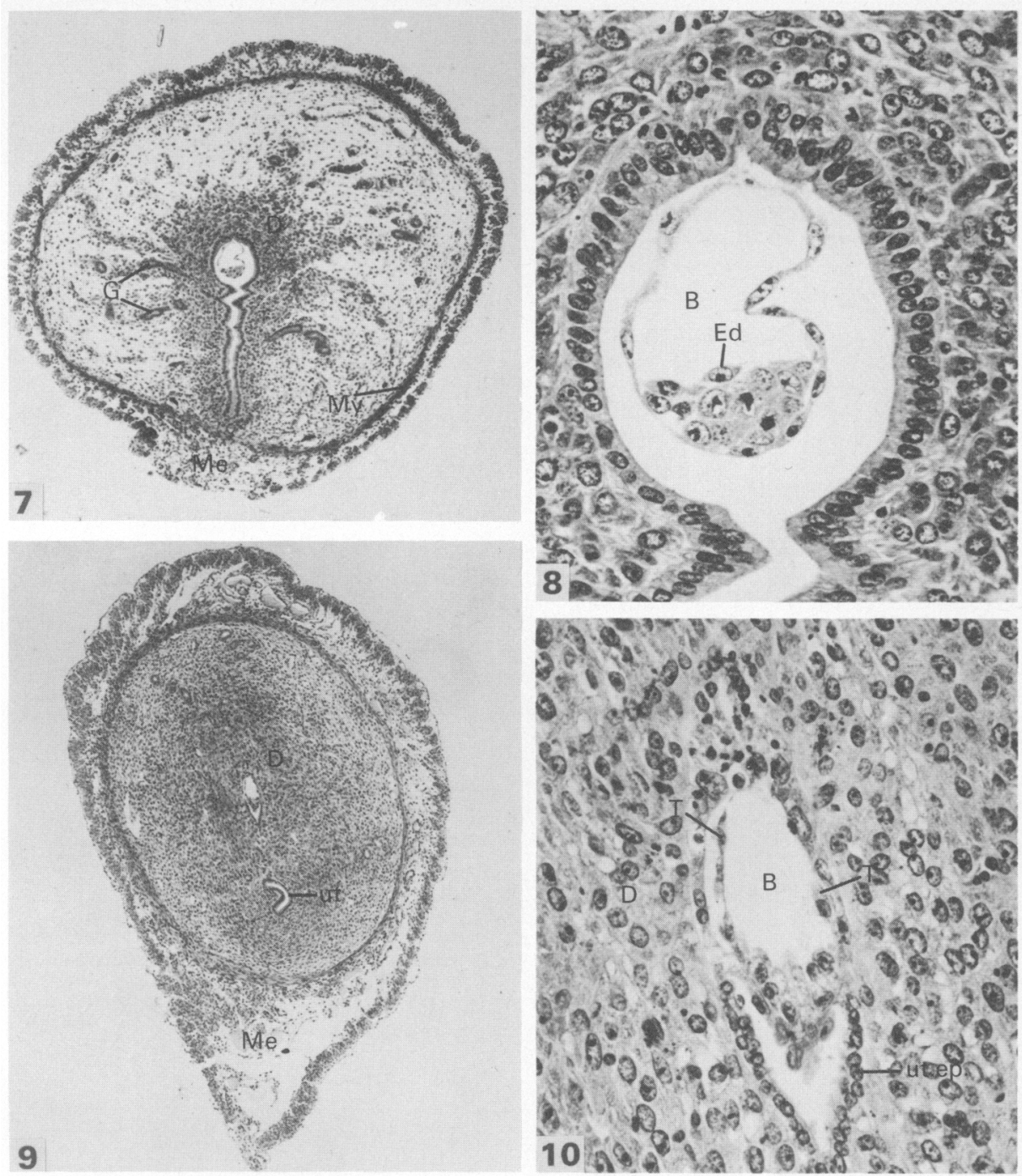

Fig. 7. Transverse section through the uterus of a mouse, about 7 days p.c., with a blastocyst, which has shed the zona pellucida, lying free in the antimesometrial groove of the slit-like uterine lumen. The dark area surrounding it (D) indicates the extent of the decidual reaction. $G$, uterine glands; My, myometrium; Me, mesometrial attachment. $\times 40$.

Fig. 8. The 'egg' region of the section shown in Fig. 7. The uterine epithelium is still intact. The enlarged decidual cells, many of them binucleate, form a dense cushion around the lumen in the vicinity of the implantation. B, blastoceoele; Ed, early endoderm. $\times 330$.

Fig. 9. Transverse section through a mouse uterus about 8 days p.c. The decidual reaction is more marked and the trophoblast has begun to erode the uterine epithelium. The hypertrophied endometrial tissue has closed around the embryo. The uterine lumen remains patent mesometrially. D, decidual reaction; ut, residual uterine lumen; Me, mesometrial attachment. $\times 35$.

Fig. 10. Part of the section shown in Fig. 9; compare with Fig. 8. T, trophoblast or trophectoderm; B, blastocoele; D, decidual cells; ut.ep., uterine epithelium. $\times 290$. 
PLATE 6
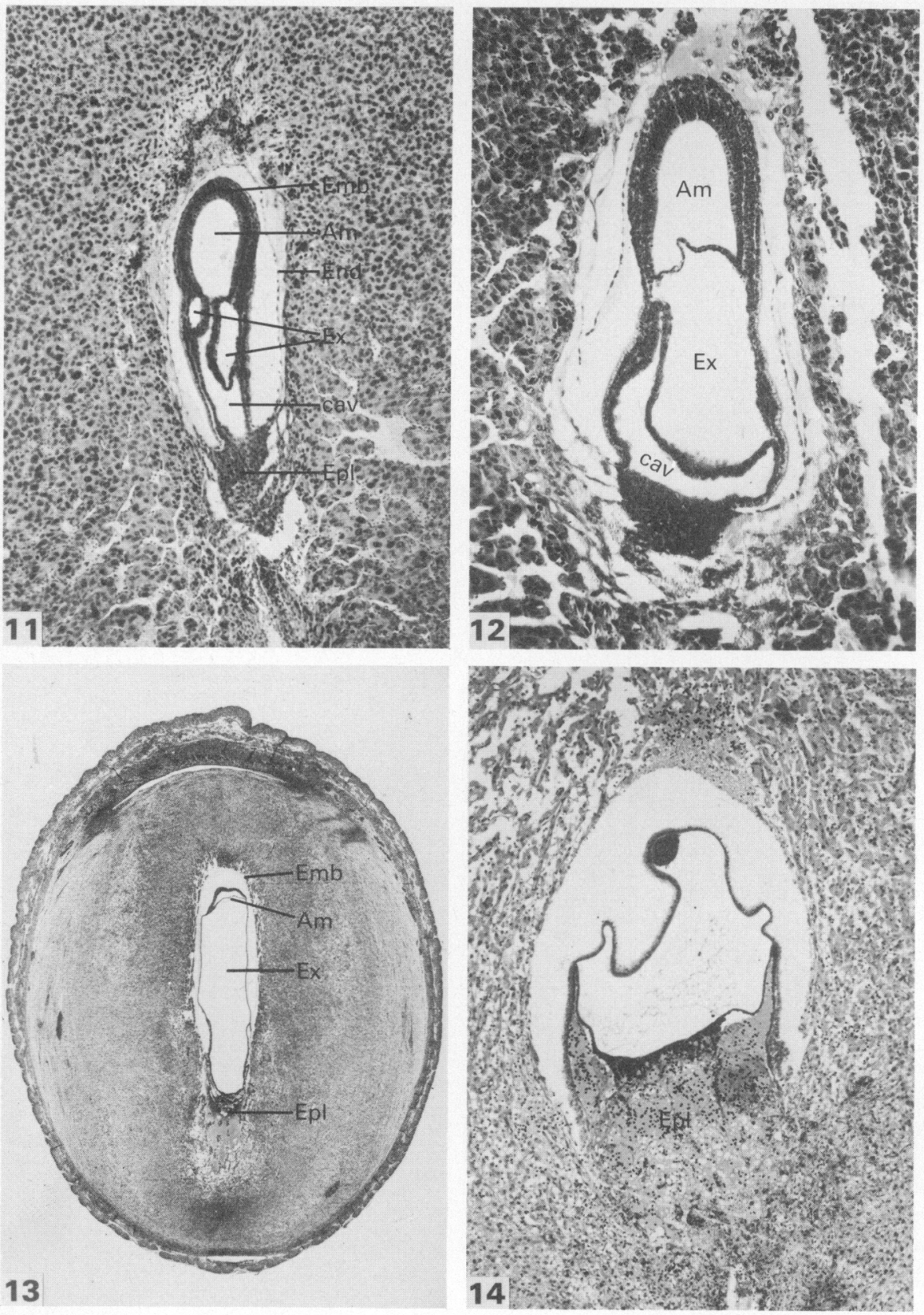

Fig. 11. Mouse embryo about 9 days p.c. The inner walls of the annular cavity in the mesoderm (the exocoele) are about to fuse and separate the amnion (top) from the ectoplacental cavity. Emb, embryo; Am, amnion; End, endoderm; Ex, exocoele; cav, 'ectoplacental cavity'; Epl, ectoplacenta. $\times 50$.

Fig. 12. Mouse embryo; the exocoele (Ex) now (a few hours after the stage shown in Fig. 11) completely separates the amniotic cavity (Am) from the ectoplacental cavity (cav). $\times 70$.

Fig. 13. Transverse section through the uterus of a guinea-pig, showing the 'egg cylinder' about 12 days p.c. Emb, embryo; Am, amnion; Ex, exocoele; Epl, ectoplacenta. $\times 7$.

Fig. 14. Early implantation (Day 26 p.c.) in the plains viscacha (Lagostomus maximus) showing the extensive invasion of the decidua by the ectoplacental trophoblast (Epl) $x_{i} x_{i} 400_{\text {tom }}$ at 04/26/2023 12:10:15PM 


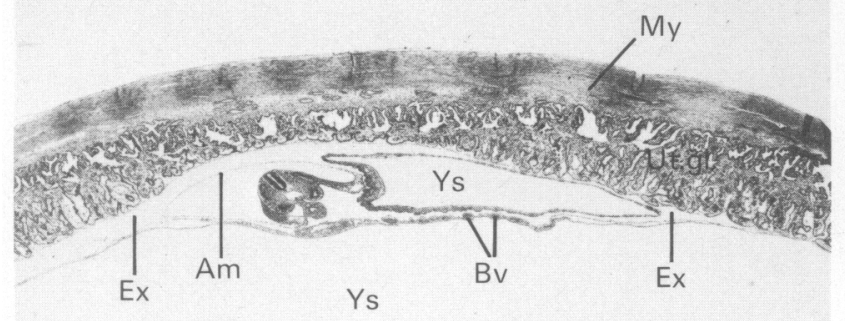

15

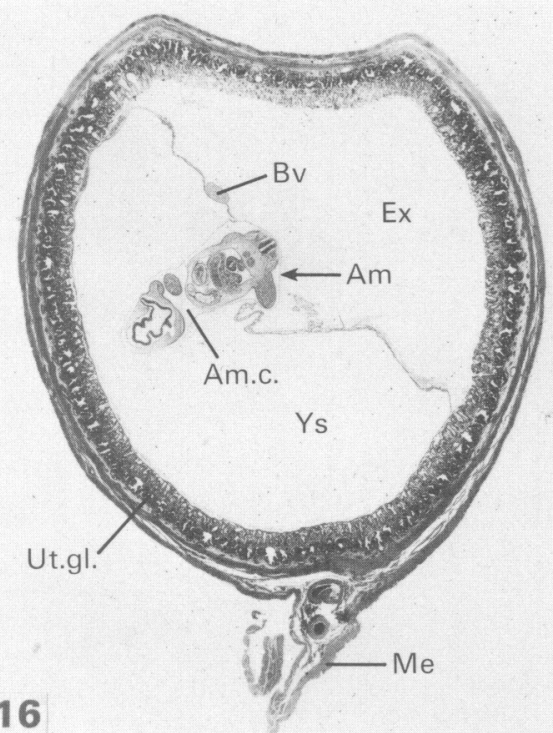

18

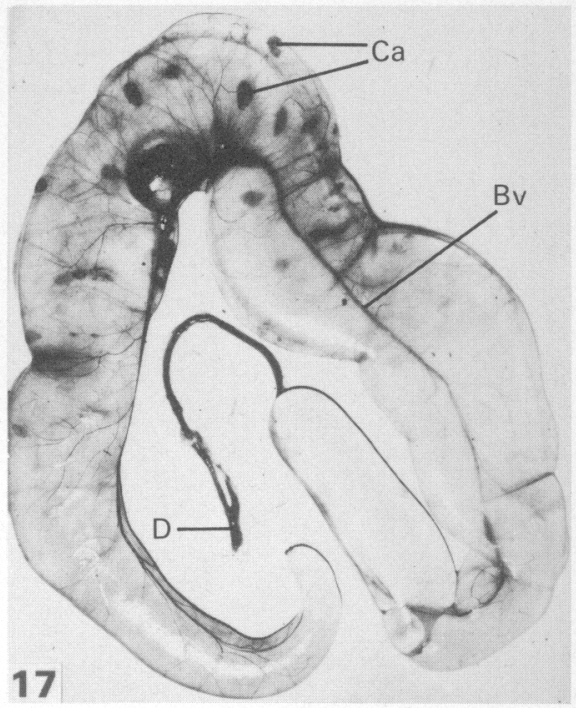

17

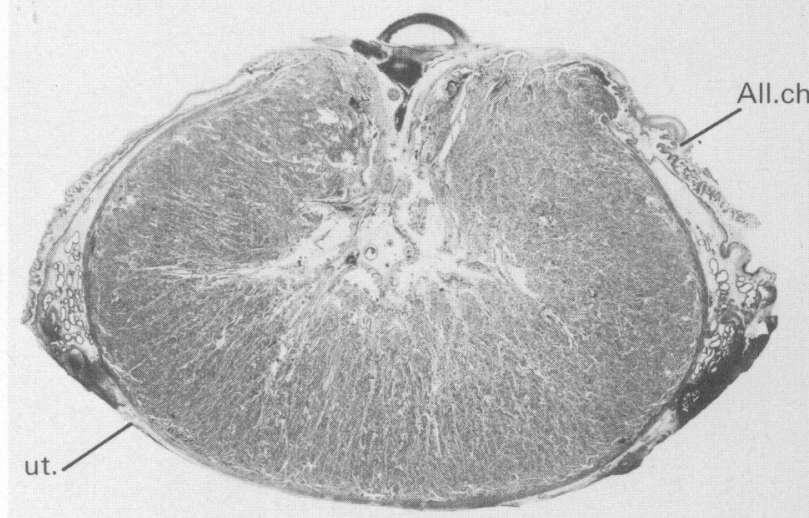

Fig. 15. Part of a transverse section through the uterus of a cat. The amnion (Am), formed by folding, is a delicate membrane covering the dorsal surface of the embryo. Ex, exocoele; Ys, yolk sac; Bv, blood vessels; Ut.g., uterine glands; $\mathrm{My}$, myometrium.

Fig. 16. Transverse section through a uterine swelling of a cat. Am, amnion; Am.c., amniotic cavity; Ex, exocoele; Ys, yolk sac; Bv, blood vessel; Ut.gl., hypertrophied uterine glands; Me, mesometrium.

Fig. 17. The allantochorionic sac, and contained embryo, of a cow, 42 days p.c. E, embryo; $\mathrm{P}$, chorionic part of placentome; Bv, blood vessel; D, degenerate tip of chorion (from the 'empty' uterine horn). $\times 0 \cdot 18$.

Fig. 18. Vertical section through one placentome ('cotyledon') of a sheep, 42 days p.c. ut, the uterine surface; All.ch., the allanto-chorion invests the fetal face of the placentome; the villi are composed of mesodermal tissue covered by ectoderm (the trophoblast); its cavity is lined by a single layer of endodermal cells. 

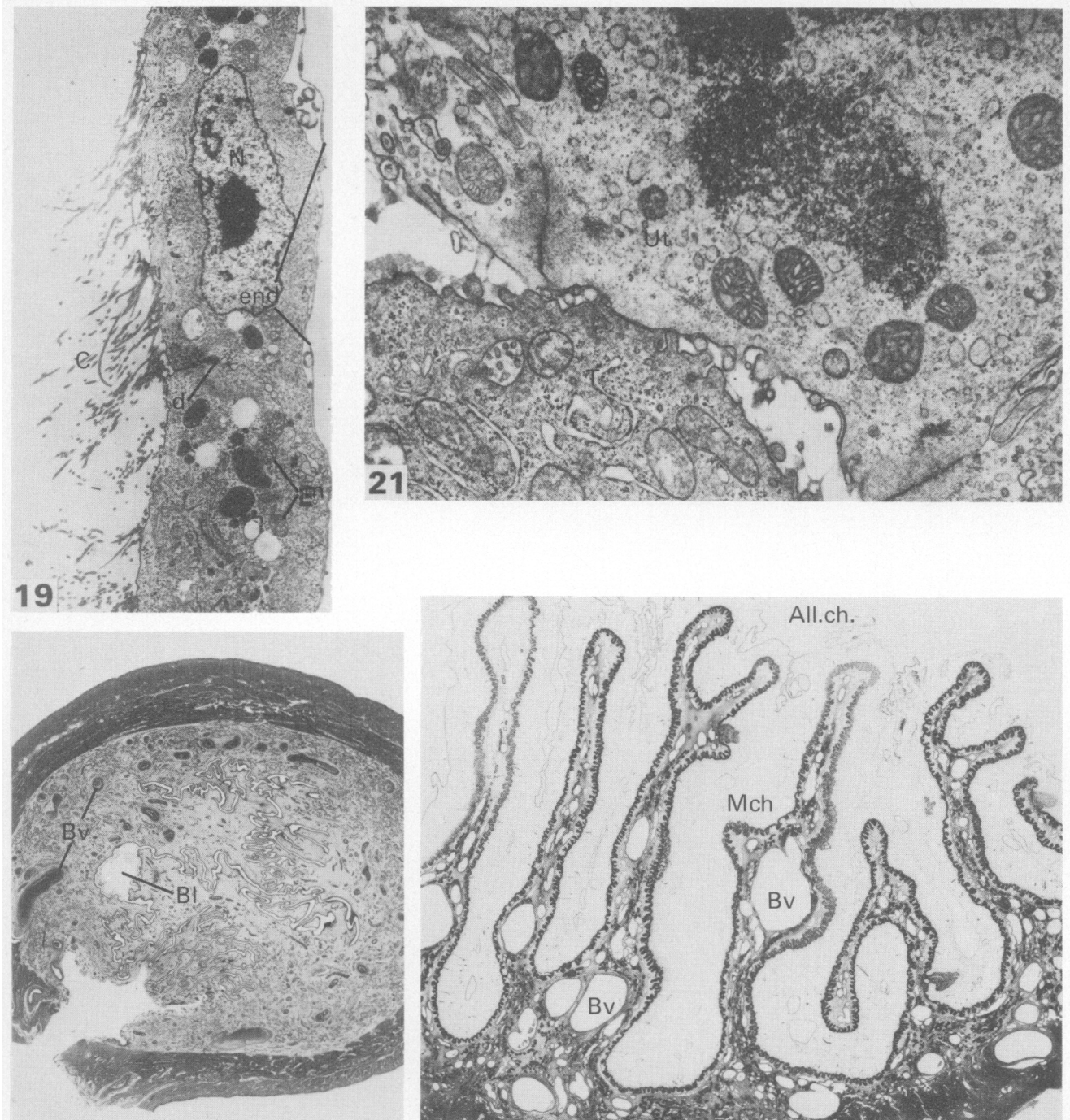

20

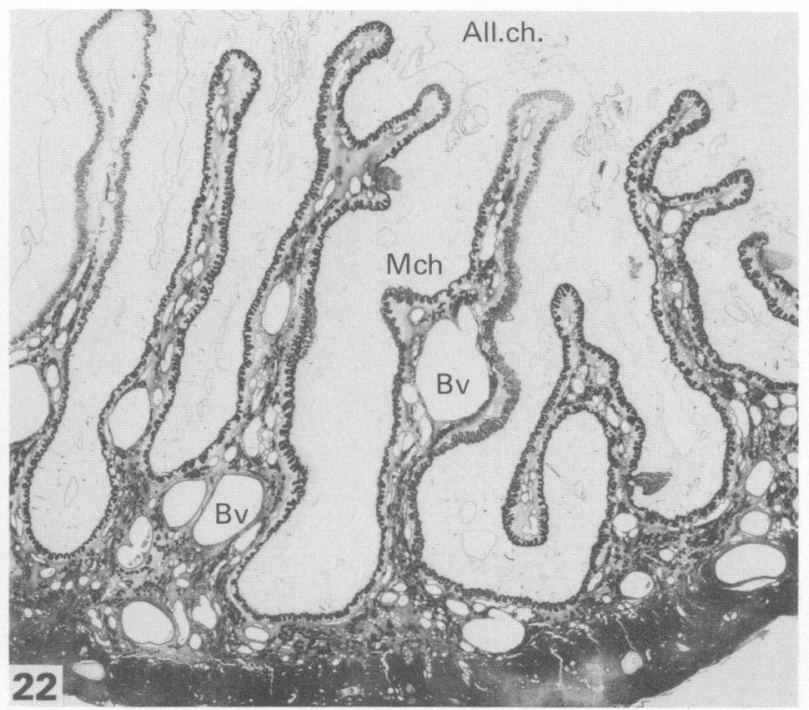

Fig. 19. Electron micrograph of a section of the wall of a pig blastocyst, 10 days p.c., showing the trophoblast bearing long microvilli $(\mathrm{C})$ on the outer surface, and the attenuated endodermal (end) cells lining the blastocoele. $d$, desmosome on the cell junction; $N$, nucleus; $m$, mitochondria.

Fig. 20. Transverse section through the uterine horn of a pig about 18 days p.c. showing the complex folds of the endometrium, such that the embryonic tissue actually contacts only a small proportion of the luminal surface. Bl, blastocyst; Bv, blood vessels. $\times 3.5$.

Fig. 21. Electron micrograph of an early point of attachment between trophoblast $(\mathrm{T})$ and uterine epithelium (Ut) in the pig. About 17 days p.c.

Fig. 22. Primary and secondary folds in the fetal-maternal attachment of the pig in mid-pregnancy. Treated with haematoxylin and eosin, the mesodermal tissue of the allantochorion is lightly stained, the endodermal lining of the allantois is thin. The tongues of maternal tissue are heavily vascularized. All.ch., the allanto-chorion, lined by allantoic endoderm; Mch, the mesenchymatous tissue of the allanto-chorion, separating the folds of maternal tissue to which the trophoblast is closely attached. Bv, blood vessels. $\times 3.7$. 


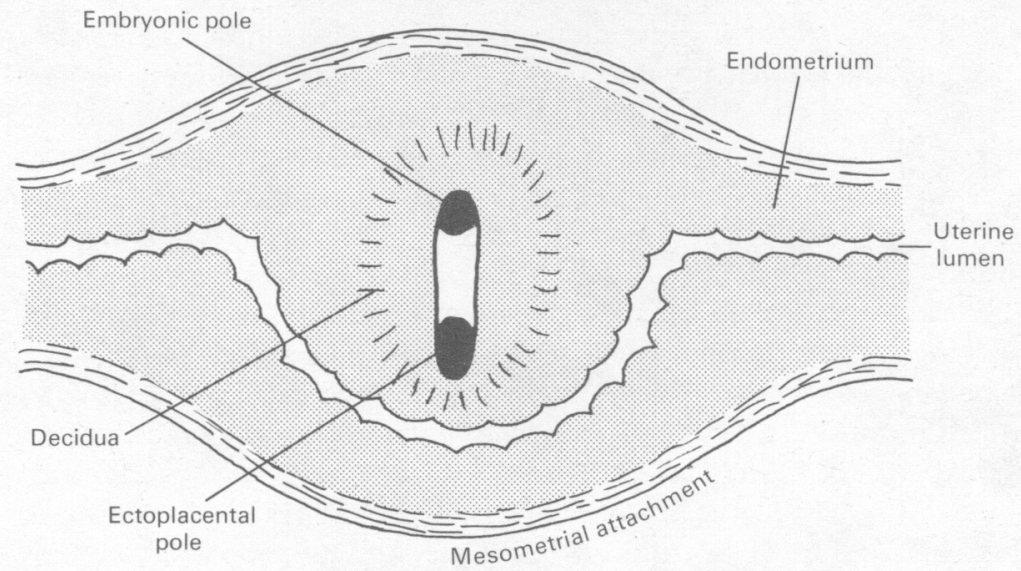

Text-fig. 4. The 'egg cylinder' of the guinea-pig as seen in a longitudinal section of the uterine swelling.

The rabbit yolk sac actually goes through the stages illustrated in Text-fig. 3, but in the guinea-pig and the murine rodents the first two steps are, so to speak, by-passed, and the yolk sac does not develop from a sac lined with endoderm. Moreover, the ectoderm of the "egg cylinder' breaks down in the middle region and at one curious stage the embryonic material consists of two separate ectodermal structures connected by a tube of very thin endoderm. How this is brought about is shown in Text-fig. 5. The ectodermal structure at the abembryonic pole is known as the 'ectoplacenta'. As will be shown, it will provide the invasive tissue of the definitive placenta.

The 'inside out' condition of the yolk sac is referred to as the 'inversion of the germ layers' in some of the older embryological texts. When first encountered it was difficult to interpret, and because great significance was thought to attach to the differentiation of the primordial germ layers their 'inversion' naturally attracted close attention. In Text-fig. 5, as in Text-fig. 1 and in Pl. 1, Fig. 2, and as is usual in embryological studies, the yolk sac is shown below the embryo or embryonic plate. In Text-fig. 4 and in Pl. 3, Fig. 5 and in other diagrams where placental relations are shown, fetal tissue appears above maternal tissue, the convention now generally adopted in placentology. The 'egg cylinder' as drawn in Text-fig. 5 is therefore 'upside down' with respect to Text-fig. 4 and Pl. 3, Fig. 5. The photomicrographs (PI. 5, Figs 7-10; Pl. 6, Figs 11 and 12) show some stages in the early development and implantation of the mouse seen in transverse sections through the uterine horn. They are orientated so that the base of the photograph is towards the mesometrium. Plate 5, Fig. 7 shows how the blastocyst, having settled at the anti-mesometrial extremity of the uterine lumen, and having shed the zona and begun to enlarge, has formed a spherical implantation chamber. There is already considerable decidual reaction, as shown by the denser endometrial tissue around the lumen, especially around the implantation chamber. This part of the same section is shown at a higher magnification in Pl. 5, Fig. 8. It will be seen that the blastocyst has reached approximately the stage of development of the guinea-pig shown in Text-fig. 5(a), but in that species the blastocyst has already penetrated the uterine epithelium and lodged in the endometrium. In Pl. 5, Fig. 8 there is an indication of breakdown of the uterine epithelium at the antimesometrial pole (top of photograph). This will become the embryonic pole of the 'egg cylinder' but as yet the ectoderm is only a tenuous layer except at the opposite pole where cell division continues and there is some indication of the first endodermal cells.

Plate 5, Fig. 9 shows the stage reached a few hours later. The uterine lumen has closed around the embryo and the endometrial decidual reaction is more pronounced. The lumen remains patent near the mesometrium. Plate 5, Fig. 10 shows the embryonic area of the same 


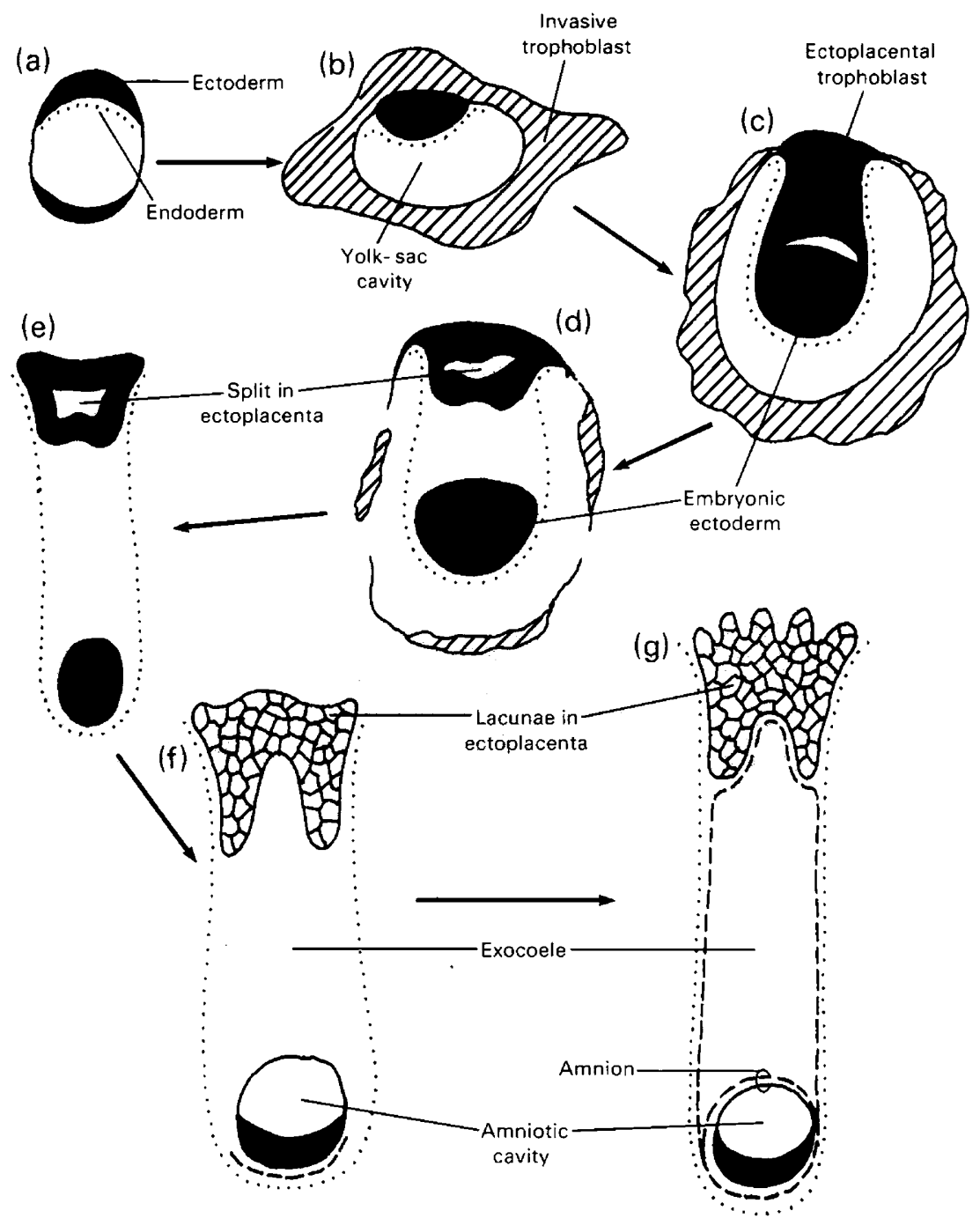

Text-fig. 5. The formation of the 'egg cylinder' in the guinea-pig. (From Sansom \& Hill, 1931.)

section in more detail. Invasion of the uterine tissue has begun, but the uterine epithelium is still intact around the mesometrial pole. The section in Pl. 6, Fig. 11 shows a considerable advance, although only about $1 \frac{1}{2}$ days later. The egg cylinder has formed by a process similar to that outlined in Text-fig. 5 and the central cavity (which Duval (1892) called the blastodermic cavity) is being bridged; the anti-mesometrial part will become the amnion and the remainder will be obliterated. This is accomplished by the development of the exocoele. It begins as a split in the mesoderm in the 'waist' of the egg cylinder, and as this split enlarges its inner walls fuse to produce the condition seen in Pl. 6, Fig. 12. This is the stage of Fig. 96 of Duval (1892) and Fig. 125d of Jenkinson (1913). Shortly afterwards, with the obliteration of the cavity at the abembryonic pole, a condition is achieved which corresponds to that of the egg cylinder of the guinea-pig (Pl. 6, Fig. 13) at a stage corresponding to that shown diagrammatically (and with reverse orientation) in Text-fig. $5(\mathrm{~g})$. As that diagram illustrates, the hystricomorphs arrive at this stage even more 'precociously' than the murines (and at 12 days, p.c. it is about one-fifth of the way through gestation; the mouse at 8 days is at mid-pregnancy). The invasive ectoderm of 
the 'ectoplacenta' at the abembryonic pole of the egg cylinder shown in Pl. 6, Fig. 13 contains numerous lacunae which fill with maternal blood as the invasive cells break down the walls of endometrial capillaries. An actively invasive placenta is, therefore, developed before the embryo itself has been differentiated to any extent. Plate 6, Fig. 14 shows this invasive region in another hystricomorph, the viscacha. The 'space' between the endoderm and the uterine wall in these two sections is artefactual, the conceptus having shrunk so that its outermost layer has lost contact with the uterine tissue to which, in life, it would be apposed. The stage of development illustrated in Text-fig. $5(\mathrm{~g})$ is approximately that of Text-fig. 4 and Pl. 3, Fig. 5(a). Then, in this type of development, as the embryo develops (Pl. 3, Figs 5b, c, d) the uterine swelling increases by distension of the exocoele, the allantois grows out from the ventral surface of the embryo, extends across the exocoele and connects with the mesoderm under the ectoplacental trophoblast to form an allanto-chorion. Meanwhile, the cushion of tissue (decidua) containing the implantation cavity loses its connection with the antimesometrial wall of the uterus and gains a connection with the mesometrial wall (Pl. 3, Figs 5b,c). As the embryo is at the anti-mesometrial end of the 'egg cylinder', the ectoplacental trophoblast, and consequently the allanto-chorionic placenta, attaches directly to the mesometrial wall of the uterus, adjacent to the entry of the uterine vessels. In this type of development the allantois is formed from a mesodermal outgrowth which is not lined by endoderm.

The guinea-pig embryo retains its connection with the 'inverted' yolk sac so that, in late pregnancy, a leash of blood vessels is found to leave the ventral region of the fetus at a point immediately anterior to the origin of the umbilical cord. This 'secondary' umbilical cord (actually the yolk-sac stalk) joins the mesoderm of the yolk sac near the antimesometrial pole of the conceptus, so the fetus is suspended within the exocoele both by the umbilicus which leads mesometrially and by the yolk-sac vessels which lead antimesometrially, an arrangement depicted in Pl. 3, Fig. 5(d). The yolk-sac (vitelline) placenta clearly plays a much more prominent part in fetal nutrition in the guinea-pig than in the pig. It persists until term and by then the decidua capsularis has been almost totally broken down and its substance absorbed by the very active cells of the yolk-sac endoderm.

\section{The fetal membranes in man}

In man, the formation of the fetal membranes (Pl. 4, Fig. 6) is even more drastically short-circuited than in rodents. As the embryo develops, it sinks into the uterine wall; the trophoblast soon thickens and its outer region becomes syncytial. Mesoderm develops early, the yolk sac is transient and there is no allantoic cavity. The allantois is represented by an endodermal diverticulum which grows into a solid mesodermal outgrowth known as the 'body stalk' which fuses with the chorion and develops blood vessels, thus forming the umbilical cord. The endodermal outgrowth constitutes the urachus. The amniotic cavity arises as a split in the embryonic knot much as it does in the guinea-pig but there is no ectoplacental mass of trophoblast. The conceptus simply enlarges within the uterine wall at the point of implantation and the overlying uterine tissue constitutes the decidua capsularis. This eventually fuses with the opposite wall of the uterus so that the uterine lumen is obliterated. The amnion enlarges as the fetus grows and before term it fills the exocoele and fuses with the chorion.

Implantation in man usually occurs in the 'posterior' (morphologically the dorsal) wall of the uterus, but its location, and therefore that of the placenta, is more variable than in most other mammals. Similarly, ectopic pregnancies (implantation and embryonic development outside the uterine cavity) are apparently more frequent in man than in other species, but of course there are few species for which comparable data are available. 


\section{The principal variants of placental form}

\section{Grosser's classification}

In mammalian pregnancy the trophoblast always provides a continuous boundary to the fetal tissue. Grosser (1909) proposed the widely used classification based on the nature of the maternal tissue with which the chorionic trophoblast finally makes contact. Where, as in the pig, the trophoblast attaches to the uterine epithelium but does not penetrate or destroy it, the condition is termed epitheliochorial. In many species trophoblastic outgrowths (villi) penetrate the endometrial tissue and acquire intimate contact with uterine blood vessels so that only the endothelium of those vessels interposes between circulating maternal blood and the surface of the chorion. This is the endotheliochorial condition found in most species of Carnivora and in some other groups. In yet other mammals, among them the rodents and man, blood is released from maternal vessels to circulate through channels within the trophoblast before returning to the maternal circulation; this is the haemochorial condition. In some species the trophoblast in parts of the placenta is indistinguishable by optical microscopy. This led to the use of the term 'haemo-endothelial' until electron microscopy showed that trophoblast, however greatly attenuated, always constituted the fetal component of the placental junction. Placentae in which there are 1, 2 or 3 layers of trophoblast in the area of contact are described as mono-, di- or tri-chorial respectively.

One further expression within this terminology has to be defined, namely the syndesmochorial type of placenta. This implies that the chorionic trophoblast is in contact with the connective tissue of the uterine endometrium, having penetrated or destroyed the uterine epithelium but not having reached the blood vessel walls. The term was formerly applied to the type of fetal-maternal connection that is typical of the 'cotyledonary' placenta of the ruminants (see below). Within the attachment areas of this type of placenta, chorionic villi penetrate into crypts in the uterine tissue and it is difficult to distinguish the uterine epithelium as such. Under the light microscope, therefore, the trophoblast appears to be in contact with the endometrial stroma, hence the term 'syndesmochorial'. Furthermore, there was evidence of the migration of binucleate cells from the trophoblast into the maternal tissue in the sheep (Amoroso, 1952). Electron microscopy, however, revealed the existence of a continuous microvillous attachment and this was assumed to indicate that this must be between trophoblast and uterine epithelium, although the cells of the maternal layer lost their lateral walls and formed a symplasma. Recent investigations (Wooding, Chambers, Perry, George \& Heap, 1980; Wooding \& Wathes, 1980) have, however, shown that binucleate fetal cells do in fact cross the microvillous boundary and their contents (including lactogen-containing granules) contribute to the symplasma. Whether or not this applies to other 'syndesmochorial' placentae has not yet been resolved, but it is increasingly realized that this terminology has descriptive convenience rather than functional significance. Electron microscopy has confirmed that fragments of fetal tissue remain attached after parturition in the sheep, as was observed by Assheton (1906), who called this a 'contradeciduate' placenta.

Gaseous exchange between mother and embryo is by diffusion between maternal and fetal blood systems, which are always brought into close contact over a relatively large surface. In haemochorial placentae the same morphological arrangement also accounts for the transfer of nutrients and removal of some waste products, but in placentae where the trophoblast is not in direct contact with circulating maternal blood the direct route is supplemented by (a) absorption by the trophoblast of material secreted by the uterine glands and/or (b) the degradation and absorption by the trophoblast of extravasated maternal blood. What follows is a description of the major kinds of placental architecture as exemplified by selected species.

\section{The 'diffuse' epitheliochorial placenta of the pig}

Plate 2, Fig. 4 shows, in diagrammatic form, a longitudinal section through the chorionic sac 
of a pig about 3 weeks p.c. when it is about $15 \mathrm{~cm}$ long. During the next 10 days or so, it approximately doubles in length and diameter and the allantois expands so that it almost fills the exocoele. It fuses with the chorion except for an area to one side of the fetus. In this region the expanding amnion itself fuses with the chorion. The fusion in each case, allanto-chorionic and amnio-chorionic, is between the mesoderm covering the allantois or the amnion and that which lines the chorion. During the 3rd week of gestation the chorion becomes attached to the uterine wall by interlocking microvilli and the fetal maternal interface is greatly increased in area by two orders of folds (Pl. 8, Fig. 12) the lesser of which are frequently referred to as 'villi' (Text-fig. 6). This placenta is termed 'diffuse' because the attachment extends over the whole surface of the chorionic sac except at its extremities and over the openings of the uterine glands. The chorion arches over the mouths of the glands and forms 'areolae', so called from their appearance as a circular spot in surface view. Some of the areolae retain this regular character throughout pregnancy but others become large and irregular in outline. The difference is more than a superficial one, for in the 'regular' areola the trophoblast cells are remarkably modified and the trophoblast becomes elaborately folded, whereas the maternal epithelial cells undergo relatively little modification. The reverse is true of the 'irregular' areola, where the uterine epithelium undergoes a remarkable transformation (Crombie, 1972). The 'regular' and 'irregular' areolae and the intervening areas of microvillous attachment thus constitute three distinct types of placental structure in the pig (Text-fig. 6), although their distribution over the chorionic surface is 'diffuse'. It may be assumed that the areolae subserve the transfer to the fetus of material derived from the secretions of the uterine glands and possibly from the uterine epithelial cells, while gaseous exchange occurs within the area of microvillous attachment, where fetal and maternal capillaries are brought into close proximity.

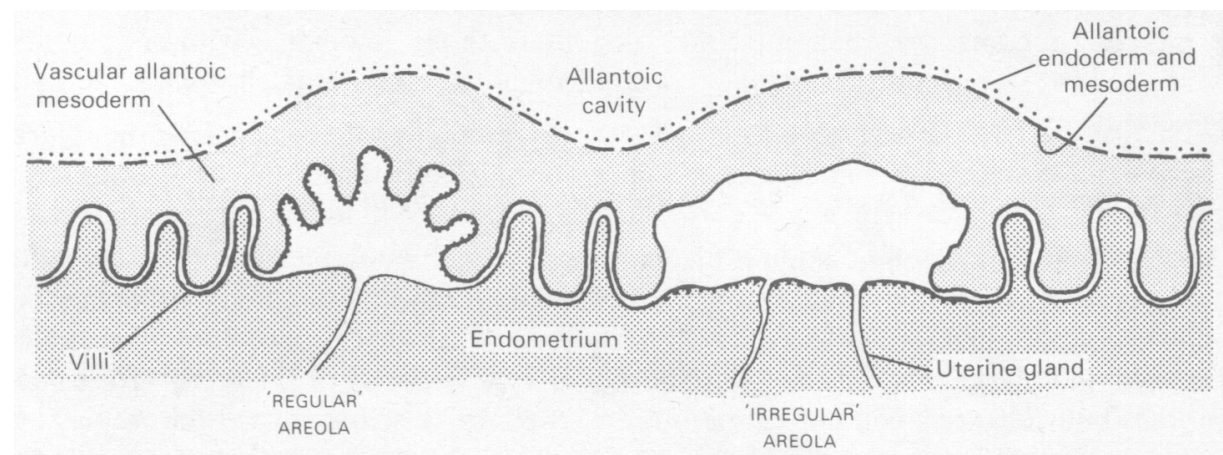

Text-fig. 6. Placental relations in the pig. Attachment is by interlocking microvilli over the secondary folds in the inter-areolar areas. Uterine glands open into the two kinds of areola. The trophoblast is markedly modified in the 'regular' areola and the uterine epithelium is altered in the 'irregular' areola.

\section{The 'cotyledonary' epitheliochorial placenta of the ruminants}

In the ruminant placenta the villous area, and attachment by interlocking microvilli, is limited to a number of knob-like 'cotyledons' (from a Greek word for a cup or socket), more usefully termed placentomes. The word 'cotyledon' may also be encountered in reference to the twin lobes of the rabbit placenta and to the minor lobulations of the placenta in guinea-pig and in man. Placentomes form at predetermined sites called caruncles on the uterine lining. In the placentome of the cow the caruncle forms a knob and the chorionic tissue covers it (Text-fig. 7a). In the sheep the caruncle forms a cup and the chorionic tissue fills it (Text-fig. 7b). Placentomes first form in the vicinity of the embryo; their fetal components are seen on the chorionic surface in Pl. 7, Fig. 17, where the conceptus has been disengaged from the uterus. The complexity of the interlocking fetal and maternal elements in the mature placentome is indicated by Pl. 7, Fig. 18. 
(a)

(b)

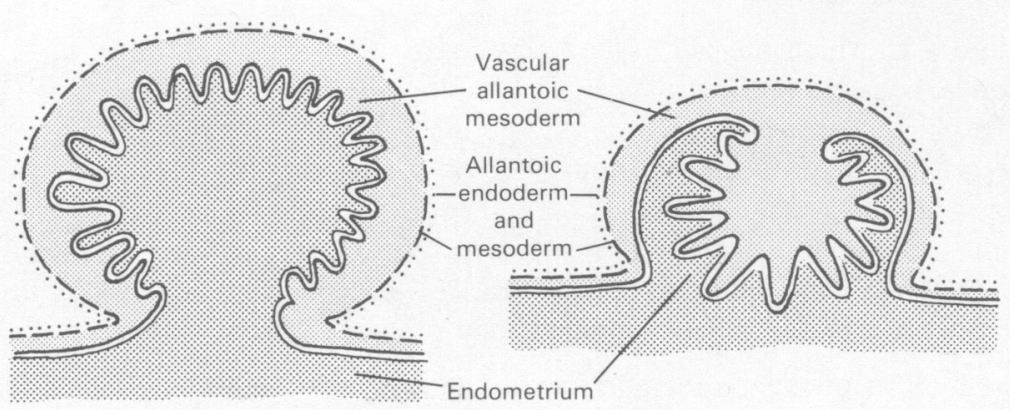

Text-fig. 7. In the placentome ('cotyledon') of the cow (a) the uterine tissue (caruncle) forms a knob which is invested by the fetal layers; in that of the sheep (b) the caruncle forms a cup into which the fetal tissue grows. The uterine epithelium breaks down in the bases of the trophoblastic crypts and maternal blood is released at these points.

In the intercotyledonary areas of the ruminant placenta the fetal and maternal epithelia are simply apposed, without interlocking microvilli, but there are modifications of the trophoblast over uterine gland openings, apparently homologous with the regular areolae of the pig. Within the placentome of the sheep, at the base of the chorionic villi, maternal blood is leaked into spaces between the maternal tissue and the trophoblast. Here, some of the extravasated erythrocytes are ingested by trophoblast cells; most of them undergo haemolysis, evidently influenced by enzymes of trophoblastic origin, producing haem compounds (e.g. uteroverdin) and releasing iron. It is presumed that this constitutes a source of iron to the fetus, and these 'haemophagous regions' are apparently homologous to those associated with endotheliochorial placentae (below). They are not equally prominent in all ruminants, however, and they are inconspicuous, in the cow.

\section{The diffuse 'microcotyledonary' epitheliochorial placenta of the horse}

This is a condition which in some respects is intermediate between that of the pig and that of the sheep and cow. In the pig, the area of gaseous exchange and microvillous attachment extends over the chorionic surface, whereas in the sheep and cow the corresponding regions are concentrated into large placentomes. In the horse (see Steven, 1975) there are homologous placentomes but they are small and numerous and they are distributed over the whole surface of the chorion. A few uterine glands open into each of the circumscribed areas between the cup-shaped 'microcotyledons', each of which is supplied by several uterine arterioles and drained by one uterine vein. Text-figure 8 represents the structure, in section, for comparison with Text-figs 6 and 7.

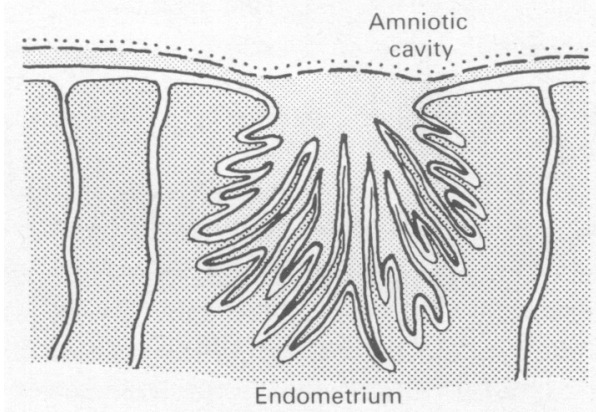

Text-fig. 8. In the horse, 'microcotyledons' occur over the area of attachment and uterine glands open onto the surface between them. 
The endotheliochorial placenta

This condition, in which uterine tissue is eroded so that the trophoblast is in contact with blood-vessel walls, is associated with superficial implantation of the 'central' type (PI. 1, Figs 1a and b) -i.e. the blastocyst enlarges within the uterine lumen and makes contact with the uterine wall over the greater part of the chorionic surface. This type of placenta, with a 'zonary' (equatorial) band of villous attachment, is characteristic of carnivores, although in some members of that order the attachment is 'discoid', being restricted to one or more sub-circular areas (see Amoroso, 1952). In the endotheliochorial placenta of the elephant the zonary band is sometimes complete but more usually it is interrupted at one or more points (Amoroso \& Perry, 1964; Perry, 1974).

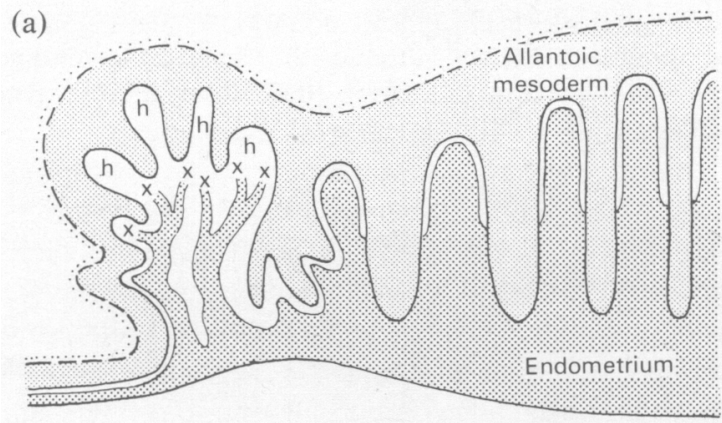

(b)

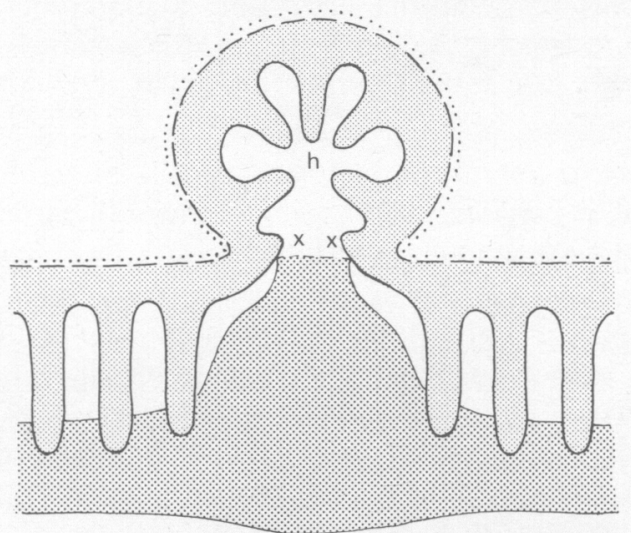

Text-fig. 9. (a) The placental margin in a carnivore (e.g. cat, dog) with a 'marginal haematoma'. Within the body of the zonary endotheliochorial placenta, the uterine epithelium is eroded around the tips of the chorionic lamellae. In the marginal haemophagous region the uterine tissue is thrown into folds; its epithelium is lost at their extremities $(x)$ and blood vessels open into the spaces (h) between the chorionic folds. (b) The central haematoma of the mustelids. The condition is essentially similar to that in canids, but the extravasated maternal blood collects into a single large haematoma.

In general, in species with an endotheliochorial placenta, the uterine glands have a less conspicuous role in gestation than they have in epitheliochorial placentae. Haemophagous regions, on the other hand, are very much more prominent, both in the carnivores and in other species (e.g. elephant) with this type of placentation. In the cat and dog (Text-fig. 9a), along both margins of the zonary band of villous attachment, maternal vessels spill blood into the uterine lumen, where it is trapped between villous-like folds of the chorion. These regions are the 'marginal haematomata'-known as the 'green border' of the placenta in the dog and the 'brown 
border' in the cat, because of the predominant colour of the breakdown products. In some carnivore species the extravasation is confined to a restricted region within the placental band, as in the 'central haematoma' of otters and badgers (Text-fig. 9b; see Enders, 1957; Sinha \& Mossman, 1966). In such a case the chorion arches to form a large sac into which many trophoblastic outgrowths project. Such a structure has sometimes been referred to as an 'haemophagous organ' (Creed \& Biggers, 1964) but all such regions are clearly homologous. In all of them maternal blood is released into what is, morphologically, part of the uterine lumen. Some of the erythrocytes are ingested entire by trophoblast cells. Their contained haemoglobin is broken down by processes which appear to be very similar to those producing bilirubin and biliverdin in the adult liver. It will be seen from Text-fig. 9a that the cavity of the (marginal) haematoma of the dog is continuous with the uterine lumen of the extra-placental part of the uterine swelling. The chorion, however, is pressed fairly closely against the uterine lining and there is little leakage of blood between it and the uterine epithelium. What little does seep into this region is 'mopped up' by the trophoblast, the cells of which, near the placental margin, often contain one or two erythrocytes. In the 'central' haematoma of the mustelid type (Text-fig. $9 \mathrm{~b})$ the cavity into which blood is shed is not in direct continuity with the extra-placental region. In such species the sac-like haemophagous structure is relatively large; in some its volume in mid-pregnancy is comparable with that of the fetus, but it is always very greatly reduced during the later stages of gestation. The haematomata or haemophagous regions associated with epithelio- or endotheliochorial placentae contain stagnant blood and are not to be confused with the haemochorial condition, in which maternal blood circulates within channels lined by trophoblast, entering these channels from maternal arterial vessels and leaving by maternal venous channels.

\section{The haemochorial placenta}

In placentae of this kind, in which maternal blood circulates through trophoblastic channels, the uterine glands have a reduced role in fetal nourishment. Similarly, there are no conspicuous haematomata (haemophagous regions). The hyena (carnivore), has a haemochorial placenta and is the only species of this Order, among those so far described, which lacks a central or marginal haematoma.

The rabbits and hares, most rodents, many bats, some insectivores and members of several other mammalian orders have a haemochorial placenta of 'labyrinthine' form, which in many respects resembles the labyrinth of the endotheliochorial placenta of the carnivores. In the great apes, and in man, the placenta is 'villous'. The distinction is between a condition in which the trophoblast covers vascularized lamellae of fetal mesenchyme (connective tissue of mesodermal origin) and one in which it covers finger-like outgrowths.

A further characteristic of the haemochorial placenta is the relative prominence of syncytial trophoblast. The trophoblast of the epitheliochorial placenta usually consists of a single-layered epithelium. In many endotheliochorial placentae the sheath of trophoblast covering the lamellae within the labyrinth consists of a layer of cytotrophoblast underlying a layer of syncytiotrophoblast which is in close contact with the endothelium of the maternal capillaries. In haemochorial placentae the syncytiotrophoblast often constitutes the bulk of the fetal placental tissue and in man the cytotrophoblast (Langhan's layer) is discontinuous in the later stages of pregnancy.

The development and structure of the haemochorial placenta has been more thoroughly studied than others, for it is the type found not only in man but also in the principal laboratory animals, the rat, rabbit and guinea-pig. The endotheliochorial placentae of the cat and dog, perhaps the next most easily accessible, have also been described in some detail but there is as yet no comprehensive account of the development of the epitheliochorial placenta of the ruminants. That of the pig has been described by Crombie (1972). Increasing attention is now being focussed on the reproduction of these species, with regard both to their economic 
importance and to fundamental problems of fetal survival and the endocrinology of pregnancy and parturition.

I thank my colleagues in the Physiology Department, A.R.C. Institute of Animal Physiology, for encouragement and help with the presentation of the material; Dr I. B. Wilson, Zoology Department, Bangor, for the loan of the mouse material in Plates 5 and 6; Dr B. J. Weir for the hystricomorph material; and Dr I. W. Rowlands for information.

\section{References}

Amoroso, E.C. (1952) Placentation. In Marshall's Physiology of Reproduction, 3rd edn, Vol. 2, pp. 127-311. Ed. A. S. Parkes. Longmans, London.

Amoroso, E.C. \& Perry, J.S. (1964) The foetal membranes and placenta of the African elephant (Loxodonta africana). Phil. Trans. R. Soc. B 248, $1-34$.

Assheton, R. (1906) The morphology of the ungulate placenta. Particularly the development of that organ in the sheep, and notes upon the placenta of the elephant and hyrax. Phil. Trans. R. Soc. B 198, 143-220.

Creed, R.F.S. \& Biggers, J.D. (1964) Placental haemophagous organs in the Procyonidae and Mustelidae. J. Reprod. Fert. 8, 133-137.

Crombie, P.R. (1972) The morphology and ultrastructure of the pig placenta throughout pregnancy. Ph.D. thesis, University of Cambridge.

du Mesnil du Buisson, F. (1961) Régression unilatérale des corps jaunes après hystérectomie partielle chez la truie. Annls Biol. anim. Biochim. Biophys. 3, 105112.

Duval, M. (1892) Le Placenta des Rongeurs. F. Alcan, Paris.

Enders, A.C. (1957) Histological observations on the chorioallantoic placenta of the mink. Anat. Rec. 127, 231-245.

Grosser, O. (1909) Vergleichende Anatomie und Entwicklungsgeschichte der Eihäute und der Placenta. W. Braumüller, Vienna and Leipzig.

Heuser, C.H. \& Streeter, G.L. (1929) Early stages in the development of pig embryos, from the period of initial cleavage to the time of the appearance of limb-buds. Contr. Embryol. Carnegie Instn 20, 1-29.

Jenkinson, J.W. (1913) Vertebrate Embryology. Oxford University Press, London.

Mossman, H.W. (1937) Comparative morphogenesis of the fetal membranes and accessory uterine structures. Contr. Embryol. Carnegie Instn 158, 129-246.

Patten, B.M. (1948) Embryology of the Pig. Blakiston, Toronto.

Perry, J.S. (1971) The Ovarian Cycle of Mammals. Oliver \& Boyd, Edinburgh.

Perry, J.S. (1974) Implantation, foetal membranes and early placentation of the African elephant, Loxodonta africana. Phil. Trans. R. Soc. B 269, 109-135.

Perry, J.S. \& Rowlands, I.W. (1962) Early pregnancy in the pig. J. Reprod. Fert. 4, 175-188.

Sansom, G.S. \& Hill, J.P. (1931) Observations on the structure and mode of implantation of the blastocyst of Cavia. Trans. zool. Soc. Lond. 21, 295-354.

Sinha, A.A. \& Mossman, H.W. (1966) Placentation of the sea otter. Am. J. Anat. 119, 521-553.

Steven, D.H. (Ed.) (1975) Comparative Placentation: Essays in Structure and Function. Academic Press, London.

Wooding, F.B.P. \& Wathes, D.C. (1980) Binucleate cell migration in the bovine placentome. J. Reprod. Fert. 59, 425-430.

Wooding, F.B.P., Chambers, S.G., Perry, J.S., George, M. \& Heap, R.B. (1980) Migration of binucleate cells in the sheep placenta during normal pregnancy. Anatomy \& Embryology 158, 361-370. 